\title{
ARTIFICIAL INTELLIGENCE IN RESEARCH AND TEACHING POLITICAL ECONOMICS OF MARXISM AND LENINISM AT UNIVERSITIES IN VIETNAM
}

\section{Linh Khanh Hoang}

\author{
Article History \\ Received: November 11, 2019 \\ Accepted: December 12, 2019 \\ Published: March 30, 2020
}

\section{Keywords \\ Political economics of Marxism and Leninism, artificial intelligence, research and teaching}

\author{
Hanoi National University of Education, Vietnam \\ Email: hkl.ajc@gmail.com
}

\section{INTRODUCTION}

During the 4.0 industrial revolution, AI is expected to be present in all areas of social life (Nguyen Manh Quan, 2018). The goal of education in the new age is not to stop at communicating. The knowledge and skills available to students that are especially important to foster their creativity, problem-solving ability, so they can create new knowledge and methods, new ways of solving new problems, contributing to enriching human knowledge. Therefore, teaching in general and teaching political economy in particular needs a strong innovation in content and methods, especially innovation of teaching and learning methods to increase students' autonomy in activities. In the current renovation of the country, the study of Political economics of Marxism and Leninism was even more urgent in order to overcome the backwardness of economic theory, dogma, and separate theory with life, contributing to the formation of new economic thinking (Le Thi Cam Nhung, 2017). And data mining tools have been successfully applied to teaching and research. Data mining software is one of the tools for data analysis. In research and teaching, it allows users to analyze data from various perspectives, classifying and aggregating (Nguyen Minh Tuan, 2016). Many countries around the world consider education, science and technology an integral part of their economic development and modernization strategies, and so do Vietnam. Although the Party and the State have issued many policies to support universities in teaching and research, assistance in developing AI in the research and teaching process is still inadequate and limited. The budget of Vietnamese universities is mainly for ordinary training activities, so the dissemination of AI tools to teachers is very limited. Although the Party and the State have issued many policies to support universities in teaching and research, assistance in developing AI in the research and teaching process is still inadequate and limited. The budget of Vietnamese universities is mainly for ordinary training activities, so the dissemination of AI tools to teachers is very limited. And in order for teachers to develop the strengths in research and teaching to bring learners the most accurate and effective amount of information, this research offers 4 AI tools namely Iris; Docear; Kopernio; Researcher, make recommendations to develop them in the research and teaching Political economics of Marxism and Leninism. These tools support teachers to access and use, shorten research time and ensure the efficiency from AI data sources.

\section{LITERATURE REVIEW}

\subsection{AI tools in research and teaching}


AI plays a very important role in research and teaching because teachers now have a great demand for long research and teaching time, so it is necessary to have tools to find materials. So AI tools for research and teaching were born. Each tool will have different advantages and disadvantages, but their common point is that it can help teachers find top quality information for research projects and more important, it will save time in determining the reliability of the information it collects. (Appenzeller, 2017).

Today, artificial intelligence is contributing to profound changes in many aspects of life, gradually becoming an important element in the colorful activities of humanity. In the next 30 years, artificial intelligence is expected to affect the entire social life, human activities, towards transforming the world in a powerful way. Artificial intelligence has the potential to become the most innovative technology in the next 10 years thanks to advances in computing power, leaps in volume, speed, diversity of data. In the field of artificial intelligence applications, speech recognition, translation, Google Translate (Google's translation tool) is considered an extremely useful product. Initially, Google's technology only recognized 3 out of 4 words you said (equivalent to 75\%). Up to now, Google can recognize up to $95 \%$ of common words. In the field of health, a study by Stanford University (United States) proved when applying algorithms to identify liver cancer, a diagnostic device of the level of specialized doctorsAI in the education market is expected to reach a market value of approximately US \$ 2 billion by 2023 and grow at a CAGR of 38\% over the period 2018-2023 (Nhu Mai, 2018).

Mark Dodgson, an innovation research professor at Queensland Business University and a visiting professor at Imperial College London, predicts how AI can change university teaching as a student's performance and how they conduct research and teaching. A team of computer scientist Christian Berger sought to bring his project on selfdriving car algorithms on the road, it encountered an ominous obstacle. Scientists at the University of Gothenburg in Sweden have found a large number of articles on this topic - more than 10,000 - in a systematic literature review. Investigating them properly will take a year. (Extance, 2018).

\subsection{The search engine AI}

The concept of AI technology first used by John McCarthy, an American computer scientist, in 1956 at The Dartmouth Conference. In the 21st century, AI techniques have undergone a revival after simultaneous advances in computer power, big data, and theoretical understanding; and AI technology has become an essential part of the technology industry, helped to solve many challenging problems in computer science, software engineering and operational research with vast data processing speeds more scale, system, science and faster than humans.

AI helps computers gain human intelligence such as thinking and solving problems, communicating by understanding languages, voices, learning and adapting. AI began to be studied in the 1940s, experienced many ups and downs, and is now very successful.

Some AI tools in research and teaching are Iris.ai; Google scholar; Refseek; Kopernio; Docear; Citeulike; Iseek; Researcher; Virtual LRC; Meta; SciPy; Jupyter; Raxter.

The following is a summary of data search tools in the research and teaching of Political Marxism and Leninism:

\begin{tabular}{|c|c|c|c|c|c|}
\hline Al tools & $\begin{array}{c}\text { Released } \\
\text { year }\end{array}$ & Documents & Customers & Fee & Link \\
\hline Iris.ai & 2016 & $\begin{array}{c}\text { More than } 134 \\
\text { millions open-access } \\
\text { documents, } \\
\text { magazines }\end{array}$ & & $\begin{array}{l}\text { Free (Paid } \\
\text { with } \\
\text { advanced } \\
\text { version) } \\
\end{array}$ & https://the.iris.ai/ \\
\hline $\begin{array}{l}\text { Google } \\
\text { Scholar }\end{array}$ & 2004 & $\begin{array}{l}\text { About } 160 \text { millions } \\
\text { documents, } 80-90 \% \\
\text { articles are published } \\
\text { in English }\end{array}$ & & Free & https://scholar.google.com/ \\
\hline Refseek & 2016 & $\begin{array}{l}\text { More than } 5 \text { billions } \\
\text { documents, } \\
\text { including websites, } \\
\text { books, encyclopedia, } \\
\text { magazines, } \\
\text { newspaper }\end{array}$ & & Free & https://www.refseek.com/ \\
\hline
\end{tabular}




\begin{tabular}{|c|c|c|c|c|c|}
\hline Kopernio & 2016 & $\begin{array}{l}\text { More than } 20000 \\
\text { academic websites }\end{array}$ & $\begin{array}{c}\text { More than } \\
250000 \\
\text { Teachers }\end{array}$ & Free/Paid & https://kopernio.com/ \\
\hline Docear & 2007 & $\begin{array}{l}\text { More than } 2 \text { millions } \\
\text { academic PDF files }\end{array}$ & $\begin{array}{l}36000 \\
\text { registered } \\
\text { member }\end{array}$ & Free & www.docear.org \\
\hline Citeulike & 2004 & $\begin{array}{c}\text { More than } 3.5 \\
\text { millions certified } \\
\text { articles }\end{array}$ & $\begin{array}{l}\text { More than } \\
900 \text { million } \\
\text { accessible } \\
\text { guests }\end{array}$ & Free & http://www.citeulike.org/ \\
\hline Researcher & 2017 & $\begin{array}{c}\text { More than } 15000 \\
\text { academic magazines } \\
\text { from } 8000 \text { scientific } \\
\text { magazines }\end{array}$ & & Free & $\begin{array}{c}\text { https://www.researcher- } \\
\text { app.com }\end{array}$ \\
\hline Jstor & 1995 & $\begin{array}{l}12 \text { millions scientific } \\
\text { articles in } \\
\text { magazines, book and } \\
\text { sources in } 75 \\
\text { specialized branches }\end{array}$ & & Free/Paid & https://www.jstor.org \\
\hline Unpaywall & 2011 & $\begin{array}{c}25.134 .891 \text { scientific } \\
\text { articles }\end{array}$ & & Free & https://profiles.impactstory.org \\
\hline Ratex & 2016 & $\begin{array}{l}\text { More than a million } \\
\text { magazine and } \\
\text { academic blogs, } \\
5000 \text { lessons, } 10000 \\
\text { recordings from } \\
\text { conferences }\end{array}$ & & Paid & https://raxter.io/ \\
\hline Meta & 2013 & $\begin{array}{c}\text { Including } 30 \\
\text { millions articles, } \\
39000 \text { magazines. } \\
\text { Data is updated daily }\end{array}$ & & Free & https://www.meta.org/ \\
\hline
\end{tabular}

\section{METHODS AND RESULTS}

\subsection{Methods}

This research is mainly based on literature analysis to selectively provide information about AI for research and teaching Political economics of Marxism and Leninism.

\subsection{Most popular AI research and teaching tools}

\section{Iris.Ai: scientific assistant}

To search for documents, teachers can use cited software such as mendelay or endnote; however, these tools only help with the creation of citations, not finding enough documents related to a certain topic. We can also use search engines like Google but in the form of listing and not search all related documents. So AI tools appeared, among which Iris is an extremely effective tool to assist teachers in searching and synthesizing documents in a very effective and thorough manner.

In August 2016, the Iris.ai blog was officially launched. Iris joined the Founders Factory in London in April 2017, being one of the first AI startups in their portfolio. Iris 5.0 was launched on May 9, 2019 with the appropriate feature that makes it easy to navigate different cells as well as to get an easier overview of relevance. There is currently a 6.0 released on December 12, 2019. 


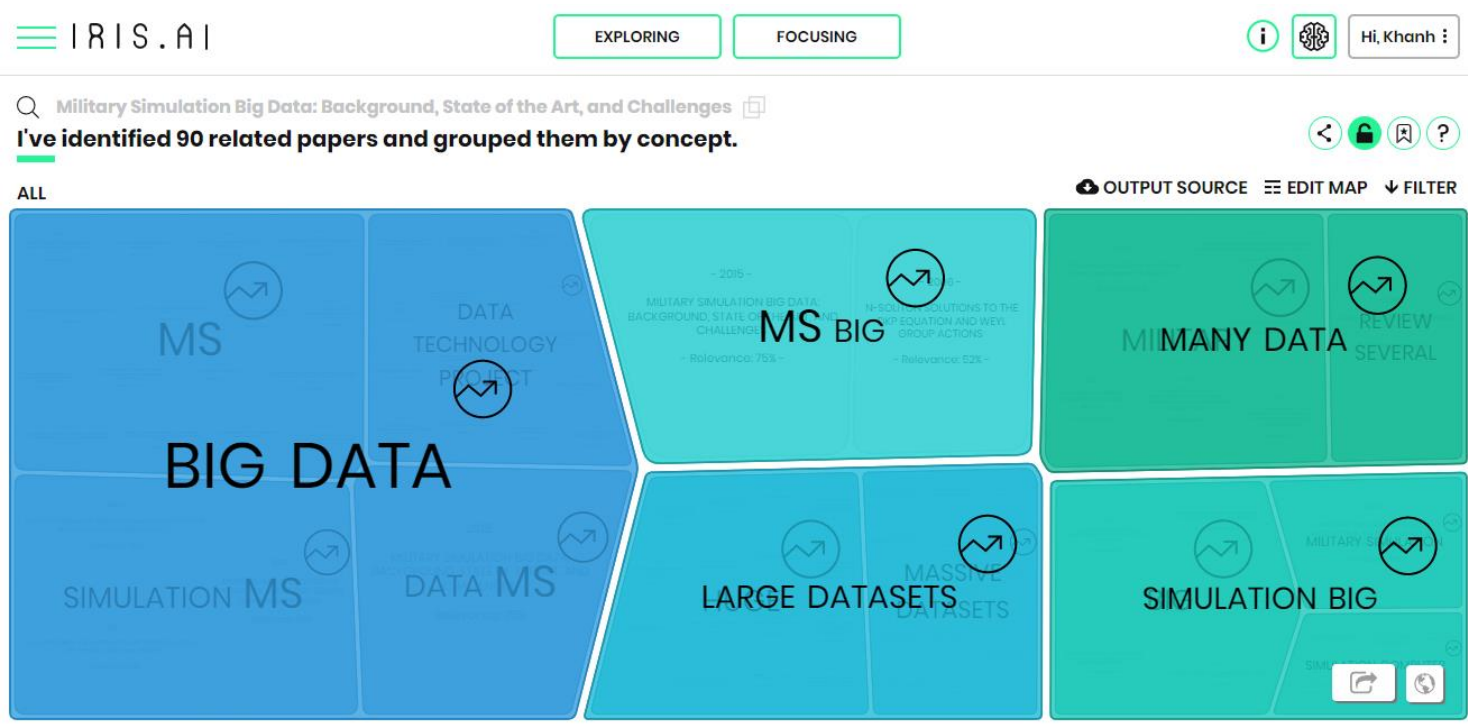

Image 1. IRIS.AI

The Iris.ai tool is based on the words that articles use to distribute them on different topics. Iris.ai leverages a database of over 134 million open articles combined with articles provided by users to provide a map for related articles. In the future, the tool's development team hopes to use AI to test every aspect of a study with other scientific literature to verify the assumptions. When the group of computer scientist Christian Berger sought to bring his project on self-driving car algorithms on the road, it encountered an ominous obstacle. Scientists at the University of Gothenburg in Sweden have found a large number of articles on this topic - more than 10,000 - in a systematic literature review. Investigating them properly will take a year, Berger said. Fortunately, they had help: a literary discovery tool provided by artificial intelligence (AI), called Iris.ai. Using a 300 to 500 word description of the researcher's problem or the URL of an existing article, the Berlin-based service returns a map of thousands of relevant documents, visually grouped by subject. The results, Berger said, provide a quick and accurate overview of what is relevant to a given research question.

Advantages and limitations of Iris.Ai tool

Advantages:

- Be a frequently updated software.

- Quick registration, easily accessible on Edge, Google Chrome, Opera, Mozilla Firefox and Safari.

- Provide D.O.I

- Give the relevant percentage of the data to the search information.

Limitations:

- There is a charge for the advanced version.

- Cannot search data by article title without access to the advanced version.

Docear: Scientific diagram

In studying and teaching Marxist Political Economy, a journal article or a research issue is often related to different topics and when carrying out such issues, the lecturer often faces difficulties in the organization of multiple interconnected issues in the same article. There have been many studies using systematization to set the logical framework and are expressed manually through mind maps. The world has produced some mind mapping software, but the common mind mapping software only serves to draw mind maps.

Docear was initiated in 2010 under the name SciPlore MindMapping by Joeran Beel and bela Gipp as part of their doctoral project. In 2011, Stefan Langer and Marcel Genzmehr joined the core group and the project received research grants for development. Docear has about 50,000 registered users and uses mind-mapsto to manage PDFs and references. From 2012 to 2015, the proposal system provided about one million proposals to more than 7,000 Teachers. (Langer \& Beel, 2017)

Docear is a set of academic documents to search, organize and create academic literature (Beel, Gipp, Langer, \& Genzmehr, 2011). Docear is a free, open source application that helps manage, cite references and design diagrams 
of thinking. Written on Java code, Docear can be compatible with many different computer generations. References can be imported directly or automatically from pre-formatted files of journals. Mind maps can be designed right in the software, saved in Mind Map format (.mm). Although the current interface is not very eye-catching, this is a very promising software in the future when incorporating many features that a researcher needs.

Advantages and limitations of Docear tool

Advantages:

Docear offers:

- A single user interface section that allows the most comprehensive organization of your literature. With Docear, you can organize documents into categories. You can organize annotations (comments, highlights and highlighted text from PDF files) into categories. You can organize annotations in PDF files and you can view multiple annotations of multiple documents, in multiple categories - at the same time.

- A 'document set concept' incorporates several tools in one application (pdf management, reference management, mind map, saving). This allows you to edit articles, exercises, theses, etc. directly in Docs and copy the annotations and references from your gallery directly into your draft.

- A suggestion system that helps you discover new documents: Docear recommends free, full-text articles, instantly available for download and tailored to your information needs.

Limitations:

- The interface is not nice, quite hard to see; the workspace is not intuitive.

- Docear lacks a feature for importing references directly from the Web.

Researcher: Simplify discovery

Each AI tool has its own advantages, features and usage methods to support the teachers' search process. Researcher was created not only to create a huge data set of different industries, but also for teachers to search for documents in a very convenient, simple and fast way.

Researcher is a software founded in 2017 by White City Center for Translation and Innovation Center 80 Wood Lane, London, W12 0BZ. The software studies over 15,000 academic journals, helping teachers track new studies from more than 8000 journals in 10 different scientific disciplines.

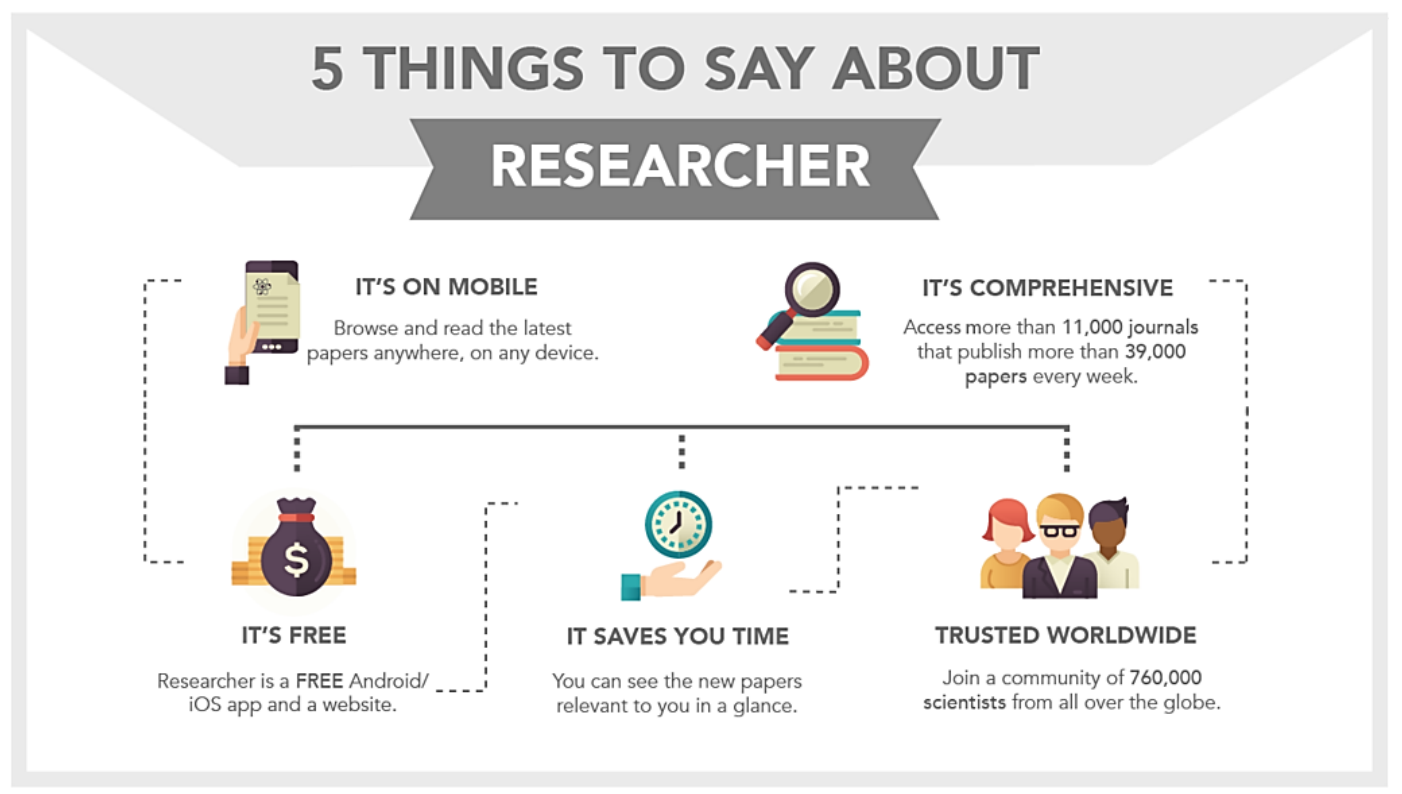

Advantages and limitations of Researcher tool

Advantages:

- Easy to browse

A social media style feed showing papers and data from your selected magazines. 
- Focus on what is important

Set up filters by keyword or author name and view your feed with the research that best suits you. Provide brief information about the journal, title, abstract and author.

- Read anytime, anywhere

Can be via web, Android and iOS. Accounts are synced across platforms to never miss the latest papers.

- Updated filter information fast

For open research, Researcher also provides direct access to the full version in PDF format. The most useful feature of this software is filtering and tracking information by Keywords. These keywords will be saved as Tab and updated regularly.

Limitations:

- Researcher does not allow filtering by time, so most users can only keep track of the latest research.

- Documents focusing on chemistry, biology and data in other fields are quite limited.

Kopernio: Optimize research

It can be seen that the support tools for teachers not only play a role in searching but also store data sources in the fastest, simplest and most convenient way. Therefore, intellectual tools such as Kopernio are also one of the useful options for teachers and lecturers of Marxist Political Economy.

Kopernio is part of the Web of Science Group, home to Web of Science, Publons and EndNote. Kopernio is a technology startup that aims to allow teachers to easily evaluate and read the full text of scientific papers established in 2016. Starting on January 15, 2020, MS Edge version 79 is born. Kopernio will search the open database and (if possible) university registries to find the best version of the article.

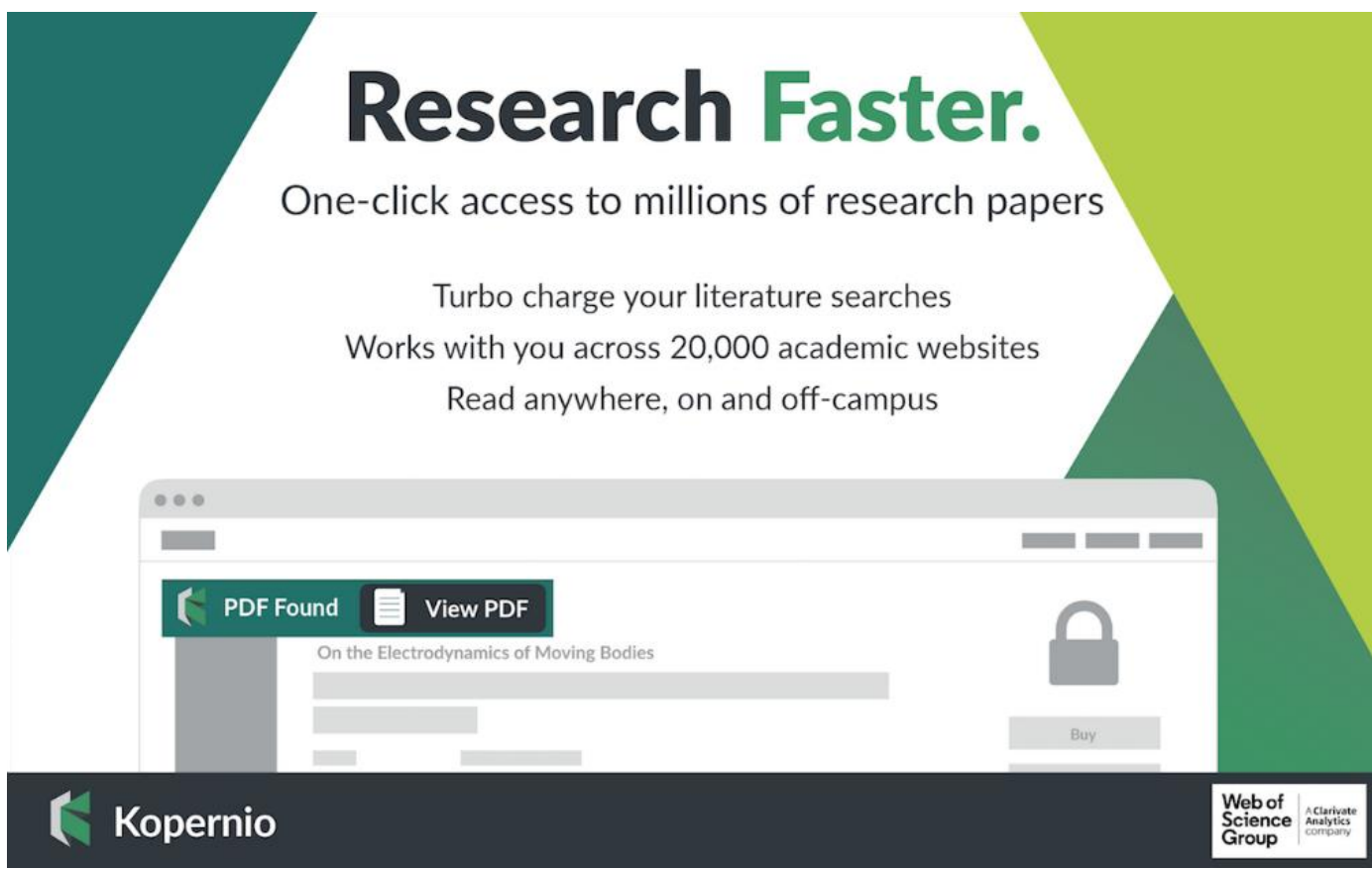

Advantages and limitations of Kopernio tool

Advantages:

- Kopernio works on thousands of scholarly websites to get full-text PDFs

- Integrate a quick search browser with Web of Science or Pubmed

Limitations:

- Can save PDF files up to $50 \mathrm{MB}$ in size. Uploading large PDF files may take longer and if there is not enough storage space, Kopernio will not be able to save the article.

- Kopernio searches for only the top 20 PDFs on the PubMed results page. 


\section{DISCUSSION AND CONCLUSION}

So with the very rapid development of the 4.0 technology revolution, AI tools have an international AI community that invests and each year develops more than 2000 AI tools, so in 1 hour there are two AI tools created. "International Data Corporation (IDC) predicts that the annual growth rate for AI globally will be 50.1\%, reaching USD 57.6 billion by 2021. This is due to investment in the retail sector. , banking, healthcare, and manufacturing, which account for more than half of AI worldwide spending". In the process of world integration, society has the right to require our country's faculty members to be stature and stand firm in the international science school. Therefore, the serious standards of international standards have been used to evaluate and recognize the merits of research and teaching Political economics of Marxism and Leninism in our country. According to the Ministry of Science and Technology, in Vietnam, since 2014, AI has been included in the list of high technologies prioritizing development investment. The Government identified this as one of the breakthrough technologies that spearheaded the Industrial Revolution 4.0 and needed to conduct research. Subsequently, in October 2018, the Ministry issued the Plan to deploy "AI Research and Development to 2025" in order to unite the parties in AI development, research, deployment and application, promoting Technology develops in key areas with strengths.

Research and teaching Political economics of Marxism and Leninism remains a weakness of Vietnamese education. Therefore, some recommendations are proposed as follows:

- It is recommended that the Government of Vietnam and the State should create more favorable conditions for the teacher community in making policies and investments to develop AI tools for research and teaching Political economics of Marxism and Leninism to promote the development of Vietnamese education in general and Political economics of Marxism and Leninism in particular. It is necessary to be strategic in order to really develop research, especially those on social sciences, which require a lot of time.

- There is a need for Vietnamization of AI tools, building and inventing AI tools for data search by a technical design team to help academics access and conduct research and teaching in an easier way.

- Creating an environment and network for teaching staff nationwide and abroad to inherit, promote, connect and discuss new findings in the use of intellectual methods and tools in the process of research and teaching Political economics of Marxism and Leninism.

Acknowledgments: This research is funded by Vietnam National Foundation for Science and Technology Development (NAFOSTED) under grant number: 02/2019/NCUD.

\section{REFERENCES}

Appenzeller, T. (2017). The AI revolution in science. Science, 1-10. https://doi.org/10.1126/science.aan7064

Beel, J., Gipp, B., Langer, S., \& Genzmehr, M. (2011). Docear: An academic literature suite for searching, organizing and creating academic literature. Proceedings of the ACM/IEEE Joint Conference on Digital Libraries, 465-466. https://doi.org/10.1145/1998076.1998188

Extance, A. (2018). AI Tames the Scientific Literature. Nature, 561, 273-274.

Langer, S., \& Beel, J. (2017). Apache Lucene as content-based-filtering recommender system: 3 Lessons learned. CEUR Workshop Proceedings, 1823, 85-92.

Le Thi Cam Nhung (2017). The research and teaching of Marxism - Leninism in the current context - difficult advantages. Retrieved February 13, 2020, from http://truongchinhtri.danang.gov.vn/?Page=duandetail\&idNews=547

Nhu Mai (2018). Artificial Intelligence in education and forecasts till 2023. Retrieved February 16, 2020, from https://techinsight.com.vn/tri-tue-nhan-tao-trong-giao-duc-va-nhung-du-bao-den-nam-2023

Nguyen Manh Quan (2018). Preparing for the future of artificial intelligence. Vietnam Science and Technology, 6, 53-55.

Nguyen Minh Tuan (2016). Application and development trend of data mining. In Open Access to Information: Motivation for Sustainable Development, pp. 106-117. 